\title{
A Case Study: Low-carb, High-fat (LCHF) Diet Combined with Fried Food in Patient with Type 2 Diabetes and Central Obesity Reduces Need for Exogenous Insulin Injection
}

\section{Cristian Baldini}

Expert and professor in clinical nutrition and diet therapy, Italy

\begin{abstract}
Eating is not a simple act of feeding our body. Diet plays a pivotal role in health promotion and chronic disease prevention. According to DGA [1] more than 117 million of American adults have one or more preventable chronic diseases, many of which are related to poor quality eating patterns and physical inactivity. These include cardiovascular disease, high blood pressure, type 2 diabetes, some cancers, and poor bone health. The importance of diet mostly as prevention for all the disorders correlated with metabolism should be strongly highlighted in this day: in fact, this clinical case shows how it's possible to decrease glycemia with diet in type 2 diabetes (T2D). Fat foods and fried foods play an unsuspected important role in Diabesity.
\end{abstract}

\section{Publication History:}

Received: November 19, 2020

Accepted: December 28, 2020

Published: December 30, 2020

\section{Keywords:}

LCHF diets, Type 2 diabetes, Lipid profile, Glycemic index, weight management

\section{Introduction}

'Diabesity' is a term for diabetes occurring in the context of obesity. Some country guidelines recommend that people with type 2 diabetes (T2D) limit their consumption of fats and cholesterol in general, which results in an unbalanced carbohydrate meal. The positive effect of LCHF diets (low carb, high-fat diets) is well documented: LCHF diets are at least as effective as other dietary strategies for reducing body weight, improving glycaemic control and reducing both hyperinsulinemia and blood glucose (reduction of $\mathrm{HbAlc}$ ) in type 2 diabetes and have unique positive effects on blood lipid concentrations and cardiovascular risk factors [2]. Despite the recommendations, foods rich in fats and cholesterol, like eggs, doesn't show any negative effect on blood lipid level in T2D patients [3]. Also, it is well-recognized that nuts, notoriously high in fats, have the capacity to lower blood cholesterol concentrations and to modify blood lipoprotein levels [4]. People that eat nuts have a lower risk of various diseases. This includes obesity, heart disease, and type 2 diabetes [5]. However, people with T2D may benefit from (good) fats consumption.

Generally, nobody talks about the different types of cooking methods and how these can affect our physio-endocrine system. The same potato boiled or fried can increase or decrease insulin. In fact, in obese insulin-resistant women, food fried in extra-virgin olive oil significantly reduced both insulin and C-peptide responses after a meal whit fried food respect the same meal whit boiled food [6].

In this case study, is show how combining both dietary strategies produces a strong effect on blood glucose, resulting in a "forced" reduction of exogenous insulin injection to avoid the problem of hypoglycemia. Blood tests after 3 months of this dietary treatment show how HbAlc was slightly improved despite the reduction of exogenous insulin injection, and a positive effect was registered in blood lipid profile (LDL, HDL, Total Cholesterol). For continuous glucose monitoring (CGM) the patient used FreeStyle Libre before and after the dietary treatment. In order to check general body functions and glycosuria, the patient used the urine test Multistix 10 SG Siemens.

\section{Objective}

This current case study shows the effects of the high-fat diet combine with fried foods as dietary interventions to lower blood glucose level and consequently reducing the amount of exogenous insulin injection. High fat diet-fried food diet not have any negative effect on blood lipoprotein levels.

\section{Materials and Methods}

\section{Design}

The patient is 67 years old at the time of the visit with type 2 diabetes, mild hypertension, $93 \mathrm{Kg}$ of weight. He has prescribed a week's renewable dietary strategy and He was instructed on how to cook the recipes, which foods, and which cooking method avoids. He was followed for 3-mo with this dietary strategy and he chek glycemia with FreeStyle Libre system every day and Glucosuria with Multistix 10 SG siemens 3 times/week.

\section{Dietary interventions}

Patient was assigned to a fried high fat/egg diet. The patient was advised weekly about his diet allocation and diet prescription, he was instructed with help of two chefs about the different cooking methods. Dairy products were excluded from the diet Was prescribed also other protein-rich alternatives such as legumes that have a low glycemic index (GI): foods as legumes have been shown to improve glycemic control in patients with type 2 diabetes mellitus (DM) [7].

Patient was given a menu with notes as a guide to the specific types of foods, cooking methods, and quantities to be consumed with particular emphasis on replacing foods containing saturated fats with foods containing MUFAs and PUFAs. Patient was also instructed not to change their activity level: in clinical trials of $\geq 8$ weeks duration structured exercise interventions reduce significantly $\mathrm{HbAlc}$ (A1C [8].

"Corresponding Author: Dr. Cristian Baldini, Expert and professor in clinical nutrition and diet therapy, Italy, Tel: 3272404224 ; E-mail: info@cristianbaldini.com

Citation: Baldini (2020) A Case Study: Low-carb, High-fat (LCHF) Diet Combined with Fried Food in Patient with Type 2 Diabetes and Central Obesity Reduces Need for Exogenous Insulin Injection. Int J Clin Nutr Diet 6: 155. doi: https://doi. org/10.15344/2456-8171/2020/155

Copyright: (c) 2020 Baldini. This is an open-access article distributed under the terms of the Creative Commons Attribution License, which permits unrestricted use, distribution, and reproduction in any medium, provided the original author and source are credited. 
Citation: Baldini (2020) A Case Study: Low-carb, High-fat (LCHF) Diet Combined with Fried Food in Patient with Type 2 Diabetes and Central Obesity Reduces Need for Exogenous Insulin Injection. Int J Clin Nutr Diet 6: 155. doi: https://doi.org/10.15344/2456-8171/2020/155

Page 2 of 5

The principles of the diet were:

1. increase the content fat from extra-virgin olive oil (EVOO)

2. use the only EVOO for frying

3. avoid any dairy product

4. increase the consumption of fatty-fish

5. pasta or toasted bread are allowed in the quantity of $50 \mathrm{~g} 3$ times a day and only in the principal meals (breakfast, lunch, and dinner)

6. do not eat between the meals: if hungry only nuts are allowed

7. drink only water if possible with fresh lemon juice without any sugar

\section{Primary outcomes}

At screening was evaluated the anthropometric measures, nutritional analysis.

Bodyweight, waist circumference, the recording of side effects, any medication changes, and a dietetic review was registered during the diet.

The primary outcome was the positive change in the level of glycemia already in the first week of diet (as shown in the results).

All other assessments were secondary outcomes.

\section{Pathology}

Blood samples were collected from laboratory for fasting blood glucose, Hb A1c, total cholesterol, HDL cholesterol, LDL cholesterol,. Blood was also collected for a full blood count, thyroid function, and liver and renal function.

\section{Secondary outcome}

There was a strong reduction of glycemia detected by different episodes of hypoglycemia.

There was no significant difference in HDL cholesterol after 3-mo of diet.

There was an improvement in total cholesterol, LDL cholesterol, from screening to 3-mo (data not shown).

There was a slight reduction of HbA1c after 3-mo of diet despite the reduction of insulin injection.

\section{Change in anthropometric measures and vital signs}

Reduction in waist circumference and blood pressure was detected.

\section{Results}

After a 3-mo dietary strategy the results were:

\section{Istantanea}

16 settembre 2018 - 30 settembre 2018 (15 giomi)

Glucosio

\begin{tabular}{lr} 
GLucosio MeDio & 126 \\
\hline$\%$ sopra intervallo & 22 \\
\hline$\%$ nelintervalo & $69 \%$ \\
\hline \% sotto intervallo & $9 \%$ \\
\hline
\end{tabular}

\begin{tabular}{lc} 
EVENTI DI \\
GLUCOSIO BASSO & 3 \\
\hline Durata media & $359 \mathrm{Mn}$
\end{tabular}

A1c stimata $6,0 \%$ ○ $42 \mathrm{mmol} / \mathrm{mol}$

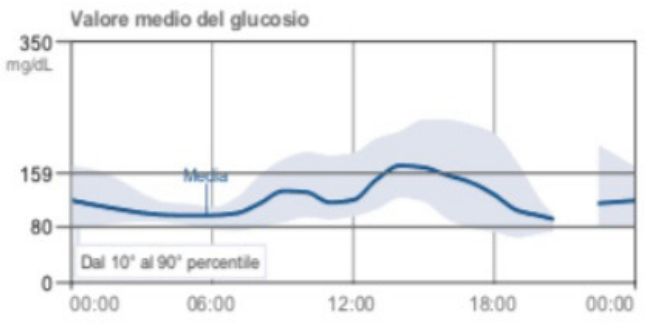

Eventi di glucosio basso

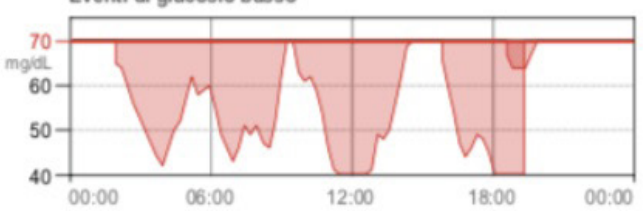

Freestyle Libre

\section{Carb. registrati}

\section{CARB}

GIORNALIERI

Insulina registrata

Insulina ad azione
rapida
Insulina ad azione
lenta
INSULINA
GIORNALIERA
TOTALE

Uso del sensore

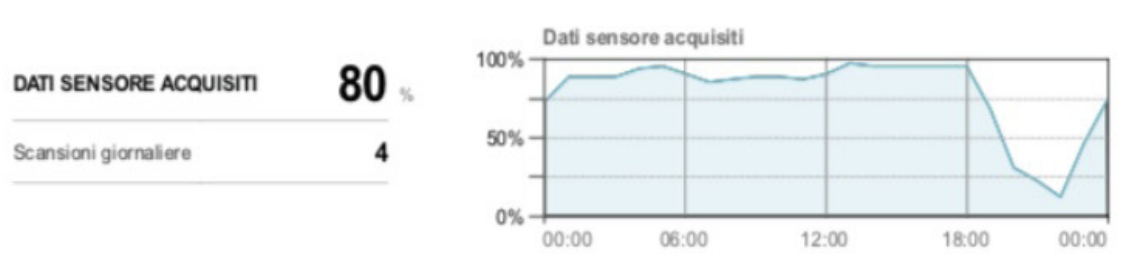

Figure 1: Glucose balance before the dietary intervention. 
Citation: Baldini (2020) A Case Study: Low-carb, High-fat (LCHF) Diet Combined with Fried Food in Patient with Type 2 Diabetes and Central Obesity Reduces Need for Exogenous Insulin Injection. Int J Clin Nutr Diet 6: 155. doi: https://doi.org/10.15344/2456-8171/2020/155

Page 3 of 5

1. improved control of glycemia that "forced" a reduction of exogenous insulin injection

2. greater satiety and better weight management

3. despite the high egg consumption, there were no differences in total cholesterol, lowdensity lipoprotein cholesterol, triglycerides, or glycemic control.

As shown in figure 1 and 2:

1. the average of glycemia was higher before $(126 \mathrm{mg} / \mathrm{dl})$ than after the diet $(104 \mathrm{mg} / \mathrm{dl})$

2. the $\mathrm{HbAlc}$ estimation was decreased after the diet (from $6.0 \%$ or $42 \mathrm{mmol} / \mathrm{mol}$ to $5.3 \%$ o $34 \mathrm{mmol} / \mathrm{mol}$ )

3. was increased the glycemia times in the range (from $69 \%$ to $71 \%$ ) and more interesting the times that the glycemia was over the range decrease from $22 \%$ to $5 \%$

4. hypoglycemic episodes were more frequently after the dietary treatment ( 25 times) than before (only 3 times)

All this data forced the endocrinologist to reduce insulin therapy.

\section{Discussion}

Diabesity it's a worldwide raising problem today, and T2D and obesity are conditions where food plays a pivotal role in treatment and prevention. The message is clear and strongly marked from the SARS-Cov-2 pandemic: we need to reverse the trend of Diabesity.
In several descriptive studies, the infected persons who died were most frequently older than 70 years, males, hypertensive, diabetics, and affected by serious comorbidities such as congestive heart failure, chronic obstructive pulmonary diseases, or renal diseases [9-17]. Males, hypertensive, diabetics, and those with COPD or major cardiovascular diseases all showed an approximately doubled risk of death or severe disease [18-21]. Obesity is also emerging as a significant, independent predictor of severe/lethal disease [22-25].

A good positive effect in the lipidic panel was detected in accordance with several studies in nondiabetic populations that showed an increase in HDL cholesterol and apolipoprotein A-I concentrations with increased egg intake, with minimal effects on LDL cholesterol [26-28]. The formation of intestinal apolipoprotein A-I, which is the major protein component of HDL cholesterol, was shown to be increased with cholesterol and fat feeding in both insulin-sensitive and, lesser, in insulin-resistant subjects [28].

This is a possible area of future research to confirm whether a high-egg diet in individuals with T2D is beneficial in raising HDL cholesterol.

Improvement in blood lipid profiles can be confounded by the trial being a weight-loss intervention. Weight loss itself has effects on blood lipid profiles that might outweigh any effects of fried/fat/egg diet on such variables. In this case study, there was a little reduction in body weight.

\section{Istantanea}

1 ottobre 2018 - 31 ottobre 2018 (31 giomi)

Glucosio

\begin{tabular}{lr}
\hline GLuCosio MEDIO & 104 \\
\hline$\%$ sopra intervallo & $5 \%$ \\
\hline$\%$ nellintervallo & $71 \%$ \\
\hline$\%$ sotto intervallo & $24 \%$ \\
\hline
\end{tabular}

VENTI DI

GLUCOSIO BASSO

Durata media
25

224 Min

\section{A1c stimata $5,3 \%$ o $34 \mathrm{mmol} / \mathrm{mol}$}

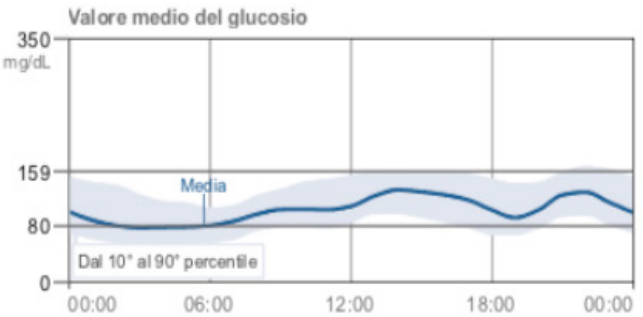

Eventi di glucosio basso

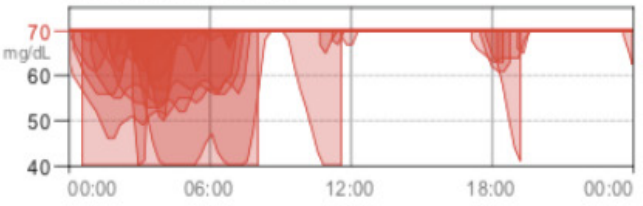

Uso del sensore

Carb. registrati

\section{CARB}

GIORNALIERI

Insulina registrata

\begin{tabular}{lr}
\hline Insulina ad azione \\
rapida
\end{tabular}

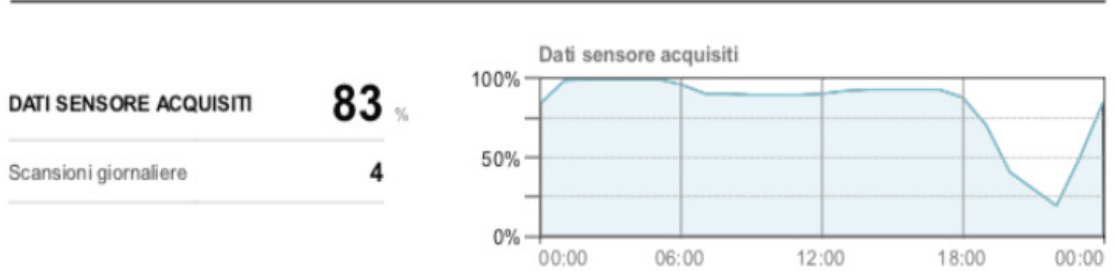

Figure 2: Glucose balance after the dietary intervention. 
Citation: Baldini (2020) A Case Study: Low-carb, High-fat (LCHF) Diet Combined with Fried Food in Patient with Type 2 Diabetes and Central Obesity Reduces Need for Exogenous Insulin Injection. Int J Clin Nutr Diet 6: 155. doi: https://doi.org/10.15344/2456-8171/2020/155

Fried food (and fat in general) was demonized in the last years. Despite this conception, their positive effect in improving postprandia insulin response in obese, insulin-resistant women was well detected. Food fried in extra-virgin olive oil improves postprandial insulin response in obese, insulin-resistant women [6]. Obese subjects have higher body weight, larger waist circumference, higher BMI, generally higher triglycerides, and lower HDL-C levels concerning lean subjects [6]. In lean healthy women, fried extra-virgin olive seem to not have any biological effect on the glycemic and insulinemic response. These findings could be attributed to the fact that the more severe the glycemic deregulation, the greater the positive effect of the addition of fat to high GI food on glycemic metabolism $[6,29]$ In contrast, fried food (in extra-virgin olive oil) reduced the insulin response and circulating C-peptide concentrations in obese women [6].

The author's responsibilities was as follows: report the principle of prescribed diet, report the data from FreeStyle Libre, report changes in the pharmacological therapy from the endocrinologist and report the blood/urine test from the laboratory. The author declare that there is no conflict of interest.

\section{Conclusions}

A person with T2D (or prediabetes) who consumed an High FatHigh Eggs-Fried Food diet can easly improve glycaemic control of blood sugar reducing (problably in variable proportion) the exogenous insulin injection. This dietary strategy seem to be one of the best external intervention for this purpose.

In according to Fuller et all. no significant difference in the change in HDL cholesterol, total cholesterol, low-density lipoprotein cholesterol was founded despite an high egg diet. Also, as claimed by Noakes in the narrative review, LCHF diet improving glycaemic control and reducing both hyperinsulinaemia and blood glucose (HbAlc) in type 2 diabetes, effects on decreasing glucose level enhanced by the presence of fried foods. It's time to revisit and update population guidelines including more eggs, more good fats and fried food (in exravirgin olive oil) in the recommended diet for health o type 2 / prediabetes/insulin-restisten peolpe.

In the western countries, reverse or better prevent conditions as obesity and type 2 diabetes can be the way to increase the general status of health population and make people more "resistent" for any unexpected adversity as SARS-Cov 2 teach.

\section{Competing Interests}

The author declare that there is no competing interests regarding the publication of this article.

\section{References}

1. https://health.gov/sites/default/files/2019-09/2015-2020_Dietary_ Guidelines.pdf

2. Noakes TD and Windt J (2017) Evidence that supports the prescription of low-carbohydrate high-fat diets: a narrative review. Br J Sports Med 51 : 133-139.

3. Fuller NR, Caterson ID, Sainsbury A, Denyer G, Fong M, et al. (2015) The effect of a high-egg diet on cardiovascular risk factors in people with type 2 diabetes: the Diabetes and Egg (DIABEGG) study-a 3-mo randomized controlled trial. Am J Clin Nutr 101: 705-713.

4. Sabaté J, Oda K, Ros E (2010) Nut Consumption and Blood Lipid Levels A Pooled Analysis of 25 Intervention Trials. Arch Intern Med 170: 821-827.
5. Jackson CL, Hu FB (2014) Long-term Associations of Nut Consumption With Body Weight and Obesity. Am J Clin Nutr 1: 408S-411S

6. Farnetti S, Malandrino N, Luciani D, Gasbarrini G, Capristo E, et al. (2011) Food fried in extra-virgin olive oil improves postprandial insulin response in obese, insulin-resistant women. J Med Food 14: 316-321.

7. Jenkins DJA, Kendall CWC, Augustin LSA, Mitchell S, Sahye-Pudaruth S, et al (2012) Effect of Legumes as Part of a Low Glycemic Index Diet on Glycemic Control and Cardiovascular Risk Factors in Type 2 Diabetes Mellitus: A Randomized Controlled Trial. Arch Intern Med 172: 1653-1660.

8. Boulé NG, Haddad E, Kenny GP, Wells GA, Sigal RJ, et al. (2001) Effects of exercise on glycemic control and body mass in type 2 diabetes mellitus: a meta-analysis of controlled clinical trials. JAMA 286: 1218-1227.

9. Garg S, Kim L, Whitaker M, O'Halloran A, Cummings C, et al. (2020) Hospitalization rates and characteristics of patients hospitalized with laboratory-confirmed coronavirus disease 2019 - COVID-NET, 14 States, March 1-30, 2020. MMWR Morb Mortal Wkly Rep 69: 458-464.

10. Yang J, Zheng Y, Gou X, Pu K, Chen Z, et al. (2020) Prevalence of comorbidities and its effects in coronavirus disease 2019 patients: a systematic review and meta-analysis. Int J Infect Dis 94: 91-95.

11. Patel AB, Verma A (2020) COVID-19 and angiotensin-converting enzyme inhibitors and Angiotensin receptor blockers: what is the evidence? JAMA 323: 1769-1770.

12. Jordan RE, Adab P, Cheng KK (2020) Covid-19: risk factors for severe disease and death. BMJ 368: $\mathrm{m} 1198$.

13. Castagnoli R, Votto M, Licari A, Brambilla I, Bruno R, et al. (2020) Severe acute respiratory syndrome coronavirus 2 (SARS-CoV-2) infection in children and adolescents: a systematic review. JAMA Pediatrics 174: 882-889.

14. Wu Z, McGoogan JM (2020) Characteristics of and important lessons from the coronavirus disease 2019 (COVID-19) outbreak in China: summary of a report of 72314 cases from the Chinese center for disease control and prevention. JAMA 323: 1239-1242.

15. Zhou F, Yu T, Du R, Fan G, Liu Y, et al. (2020) Clinical course and risk factors for mortality of adult inpatients with COVID 19 in Wuhan, China: a retrospective cohort study. Lancet 395: 1054-1062.

16. Zuin M, Rigatelli G, Zuliani G, Rigatelli A, Mazza A, et al. (2020) Arteria hypertension and risk of death in patients with COVID-19 infection: systematic review and meta-analysis. J Infect 81: e84-e86.

17. Bravi F, Flacco ME, Carradori T, Volta CA, Cosenza G, et al. (2020) Predictors of severe or lethal COVID-19, including Angiotensin converting enzyme inhibitors and Angiotensin II receptor blockers, in a sample of infected Italian citizens. PLoS One 15: e0235248.

18. Matsushita K, Ding N, Kou M, Hu X, Chen M, et al. (2020) The relationship of COVID-19 severity with cardiovascular disease and its traditional risk factors: a systematic review and meta-analysis. Glob Heart 15: 64.

19. Williamson E, Walker AJ, Bhaskaran K, Bacon S, Bates C, et al. (2020) OpenSAFELY: factors associated with COVID-19-related hospital death in the linked electronic health records of 17 million adult NHS patients. MedRxiv.

20. Mehra MR, Desai SS, Kuy S, Henry TD, Patel AN, et al. (2020) Cardiovascula disease, drug therapy, and mortality in covid-19. N Engl J Med 382: 2582.

21. Garg S, Kim L, Whitaker M, O'Halloran A, Cummings C, et al. (2020) Hospitalization rates and characteristics of patients hospitalized with laboratory-confirmed coronavirus disease 2019 - COVID-NET, 14 States, March 1-30, 2020. MMWR Morb Mortal Wkly Rep 69: 458-464.

22. Williamson E, Walker AJ, Bhaskaran K, Bacon S, Bates C, et al. (2020) OpenSAFELY: factors associated with COVID-19-related hospital death in the linked electronic health records of 17 million adult NHS patients. MedRxiv.

23. Simonnet A, Chetboun M, Poissy J, Raverdy V, Noulette J, et al. (2020) High prevalence of obesity in severe acute respiratory syndrome coronavirus-2 (SARS-CoV-2) requiring invasive mechanical ventilation. Obesity 28: 1195 1199.

24. Lighter J, Phillips M, Hochman S, Sterling S, Johnson D, et al. (2020) Obesity in patients younger than 60 years is a risk factor for Covid-19 hospital admission. Clin Infect Dis 71: 896-897.

25. Pearce KL, Clifton PM, Noakes M (2011) Egg consumption as part of an energy- restricted high-protein diet improves blood lipid and blood glucose profiles in individuals with type 2 diabetes. Br J Nutr 105: 584-592. 
Citation: Baldini (2020) A Case Study: Low-carb, High-fat (LCHF) Diet Combined with Fried Food in Patient with Type 2 Diabetes and Central Obesity Reduces Need for Exogenous Insulin Injection. Int J Clin Nutr Diet 6: 155. doi: https://doi.org/10.15344/2456-8171/2020/155

Page 5 of 5

26. Mutungi G, Ratliff J, Puglisi M, Torres-Gonzalez $M$, Vaishnav $U$, et al (2008) Dietary cholesterol from eggs increases plasma HDL cholesterol in overweight men consuming a carbohydrate-restricted diet. J Nutr 138: 272276.

27. Knopp RH, Retzlaff B, Fish B, Walden C, Wallick S, et al. (2003) Effects of insulin resistance and obesity on lipoproteins and sensitivity to egg feeding. Arterioscler Thromb Vasc Biol 23: 1437-1443.

28. Howlett J, Ashwell M (2008) Glycemic response and health: sum- mary of a workshop. Am J Clin Nutr 87: 212-216. 